The special point about the contribution of Barnes is the significance he attaches to age; that extension injury is more common in those with relatively rigid necks and naturally therefore in the later decades of life. This is a first-rate piece of observation, supported by Taylor and Blackwood, for in such circumstances new mechanics must obviously apply.

The suggestion is made that in the majority of cases where there is cord injury up to a level, but with no evidence of displacement, the injury has usually been occasioned in this manner, by hyper-extension. With the exceptions drawn from very gross flexion joint ruptures it seems that they have gone far towards proving their point. If this conclusion is substantiated by other observers, and it probably will be, we have found an answer to a problem which has puzzled surgeon and neurologist alike for over a century. A virtue of this clarification will be the disposal of spinal concussion, a state of which some have written as if it could occur without anything coming into contact with the cord-an absurd notion indeed.

The part played by extrusion of disc tissue in causing damage of the cord has come to the forefront in recent years. So long ago as 1909 Thorburn wrote " more rarely the damage is done ... from the forcing back of intervertebral cartilage which forms a projecting shelf pressing against the cord " (Burghard's " System of Operative Surgery "). It would be untrue to suggest that Thorburn considered this to be a really significant feature of spinal trauma. He observed it, as had many others, at necropsy but regarded it as scarcely more than part of the disturbance of normal relationships produced by great violence. He was unable to illustrate it as an isolated event and proposed no particular treatment. In recent times the present writer has considered it a more serious feature (Proceedings of the Royal Society of Medicine, 1940, 651) and a discussion a few weeks ago in London is reported in detail in this number of the Journal. Beyond doubt further observations will put it in proper perspective.

The real problem of spinal injury is not altered materially by change of opinion as to what the agent of injury may be. If the cord has been badly damaged it is still fruitless to operate. If laminectomy alone had been the right step then older surgeons, who did this operation in cases of injury much more often than we do to-day, should have had far more success than, in fact, they had. But Barnes is quite right in pointing out that total extinction of cord function can occur without haemorrhage into the cord, a fact with which this writer has long been impressed (British Medical Journal, 1936, 1125). Unhappily, it does not follow that recovery is possible, for disruption of neural elements can occur without bleeding. The cord is not so vascular a structure that it cannot be damaged bluntly without haemorrhage.

The two papers published in this number have the virtue of that brevity and clarity with which new ideas are best expressed.

GEOFFrEY JeFFERSON.

\title{
TRAUMATIC URAEMIA
}

"More lives have been lost than ever were saved by the use of the tourniquet." Why does the prolonged application of a tourniquet cause death from uraemia? Is this complication the same as the uraemia of the crush syndrome? Is it safe to believe that in such cases life can be saved by amputation? What is the relationship between crush and tourniquet anuria, the anuria of mismatched blood transfusion and blackwater fever, and the uraemia of surgical shock?

In our last number we reviewed the work of Trueta, Barclay, Franklin, Daniel, and Pritchard who, in " one of the most remarkable researches in recent years," showed that there is a dual circulation in the kidney under sympathetic control which can be stimulated by arterial injury in the lower limb. The relationship between the anuria of cortical renal ischaemia due to lower limb injury, that of renal tubule blockage by the products of mismatched transfusion, and of renal anoxia due to fluid loss and shock, are not yet fully elucidated. In this number of the Journal we have invited from Dr Darmady a critical review on the subject of traumatic uraemia, and in a forthcoming number of the Journal we hope to publish a contribution on orthopaedic applications of the recent researches in Oxford.

EDITOR.

VOL. 30 B, No. 2, MAY 1948 